\title{
Application of SWAT model to Assess Land Use and Climate Changes Impacts on Hydrology of Nam Rom River Basin in Vietnam
}

\author{
$\underline{\text { Ngo Thanh Son }}^{1 *}$, Hoang Le Huong ${ }^{2}$, Tran Trong Phuong ${ }^{3}$, Nguyen Duc Loc $^{3}$ \\ ${ }^{1}$ Department of Water Resources, Faculty of Land Management, Vietnam National University of \\ Agriculture, Vietnam, 100000 \\ ${ }^{2}$ College of Forestry and Natural Resources, University of the Philippines LosBanos, College, \\ Laguna, Philipines 4031 \\ ${ }^{3}$ Department of Geodesy and Cartography, Faculty of Land Management, Vietnam National \\ University of Agriculture, Vietnam, 100000 \\ *Corresponding author. Tel.: +84-914-346-264, Fax: +84-243-8276-554 \\ E-mail address: ntson@vnua.edu.vn
}

\begin{abstract}
Land use/land cover (LULC) and climate changes are two main factors directly affecting hydrologic conditions. However, very few studies in Vietnam have investigated changes in hydrological process under the impact of climate and land use changes on a basin scale. The objective of this study is to assess the individual and combined impacts of land use and climate changes on hydrological processes for the Nam Rom river basin, Northwestern Viet Nam using Remote Sensing (RS) and Soil and Water Assessment Tools (SWAT) model. SWAT model was used for hydrological process simulation. Results indicated that SWAT proved to be a powerful tool in simulating the impacts of land use and climate change on catchment hydrology. The change in historical land use between 1992 and 2015 strongly contributed to increasing hydrological processes (ET, percolation, ground water, and water yield), whereas, climate change led to significant decrease of all hydrological components. The combination of land use and climate changes significantly reduced surface runoff $(-16.9 \%)$, ground water $(-5.7 \%)$, water yield $(-9.2 \%)$, and sediment load $(-4.9 \%)$. Overall climatic changes had more significant effect on hydrological components than land use changes in the Nam Rom river basin during the 1992-2015. Under impacts of projected land use and climate change scenarios in 2030 on hydrological process of the upper Nam Rom river basin indicate that ET and surface flow are more sensitive to the changes in land use and climate in the future. In conclusion, the findings of this study will basic knowledge of the effects of climate and land-use changes on the hydrology for future development of integrated land use and water management practices in Nam Rom river basin.
\end{abstract}

Keywords: Climate Change, Hydrology, Land Use Change, Remote Sensing, SWAT, Nam Rom River Basin.

\section{Introduction}

Climate and land use changes are expected to alter regional hydrologic conditions and results in a variety of impacts on water resources and soil erosion throughout the world [4, 9, 22]. Climate change could possibly to affect the hydrological cycle with changes in temperature and precipitation, which may lead to changes in water availability as well as the transformation and transport of pollutants [21]. Changes in land-use such as a result of deforestation, agricultural expansion, and urbanization have altered surface runoff generation and have then affected the hydrological processes and the transport of pollutants [3]. As a result, climate and land-use are identified as main factors controlling the hydrological and sediment behavior of catchments [5]. It is important to understand the hydrological and sediment responses to these changes in order to develop strategies for land-use planning and water resource management. Studies of the hydrological and water 
quality impacts of climate change and land-use change are desirable [10].

With the expansion of Remote Sensing (RS) capabilities and the model available presently, a physically based distributed model has been developed to simulate runoff and erosion dynamics of larger and more complex catchments. Among the most widely used computer simulation modelling techniques for predicting runoff and sediment yield, Soil and Water Assessment Tool (SWAT) is selected to simulate soil erosion and runoff because of its availability and also because it is userfriendly in handing input data and can be applied to a large basin [2]. SWAT is a spatially distributed, physical based model in which hydrologic processes including surface runoff, actual evapotranspiration, recharge, and streamflow have been simulated, calibrated, and validated worldwide at a variety of spatial and temporal scales to address different hydrological and environmental issues [20]. In addition, SWAT is tested in various world climates from arid and semi-arid regions to humid and tropical areas [17]

Since 1993, SWAT has proven to be an effective tool for simulating flow, water quality and soil erosion in small to large complex basins all over the world including Vietnam. Many studies have discussed the impacts of land use and climate change on hydrology and sediment yield [7, 9, 11, 18, 19, 23]. The simulation results of all previous studies indicated that change in climate and forest types have significant impact on flow and sediment transport, however, no clear distinction was made between individual and combined effects of land use and climate change on hydrological responses. To our best knowledge, there are very few RS and SWAT researches that focus on evaluating and predicting water resources and sediment yield in the tropical areas like Vietnam, Thailand, Myanmar, Lao, Cambodia and Philippines, etc. This may be because of limited temporal and spatial data and data reliability in developing countries. Therefore, this study plays an important role in developing SWAT application in the northwest region of Vietnam which comprise a Nam Rom river basin where mountainous high land use changes and climate variability are the subject of high stream flow as well as severity increasing of flood and droughts. In addition, a deep understanding of hydrological processes can provide the experience and techniques to be possibly applied to other river basins in Vietnam and Southeast Asia.

The general objective of this study is to quantify the impacts of the past land-use change and climate change on hydrological responses and sediment yield - a case study of a catchment in Vietnam. The objectives of this study are to: (1) quantify the major land use change between 1992 and 2015, (2) set-up, calibrate, and validate the SWAT model; (3) evaluate the historical effect of land use changes and climate variability on hydrological components (surface runoff, base flow, water yield, soil and water contents and evaporation), (4) evaluate the projected land use and climate change on hydrological components, and (5) provide important guiding information to decision-makers for a future development plan as well as measures implement appropriate watershed management and sustainable development.

\section{Study area and data collection}

\subsection{Description of the Project Area}

The Nam Rom river basin is located in the Northwest of Vietnam between $21^{\circ} 00^{\prime}$ to $27^{\circ} 02^{\prime} \mathrm{N}$ and from $102^{0} 88^{\prime}$ to $103^{0} 28^{\prime} \mathrm{E}$ covering a total area of $1348 \mathrm{~km}^{2}$ with elevation varying from 436 to $2019 \mathrm{~m}$ above mean sea level (Fig 1). The topography ranges from valley to gentle slope, to steep slope. The slope of mountainous areas in the northwest region ranges from $20^{\circ}$ to $35^{\circ}$. The Nam Rom River Basin has a subtropical monsoon climate with a mean annual rainfall of 1000 to 2100 $\mathrm{mm}$ but $75 \%$ of the rainfall falling in May through October. The maximum temperature can exceed 
$40^{\circ} \mathrm{C}$ in the summer and the minimum temperature falls below $3^{\circ} \mathrm{C}$ in the winter. Most parts of the area are dominated by soils such as Ferralsols, Fluvisols, and Acrisols, which are the remains of ancient soils on slopes after exposure from severe soil erosion (MONRE, 2015). Major land use types in the Nam Rom river basin are forests (45.87\% of the total area), field crop (35.23\%), and perennial crop $(10.57 \%)$. The remaining land use types are paddy $(3.69 \%)$, urban $(3.14 \%)$, water $(0.51 \%)$, and other land $(0.99 \%)$. The major crops cultivated in this area include lowland rice, upland rice, maize, cassava, acacia, and rubber. The annual report from the Ministry of Natural Resources and Environment (MONRE) in 2015 showed that the area is characterized by land use changes, soil degradation and nutrient losses associated with massive deforestation in the last 20 years, expansion of agricultural activities, and inappropriate conservation practices. Besides, it is considered as one of the most disaster-prone regions, suffering from tropical storms, landslides, soil erosion, and forest fires.

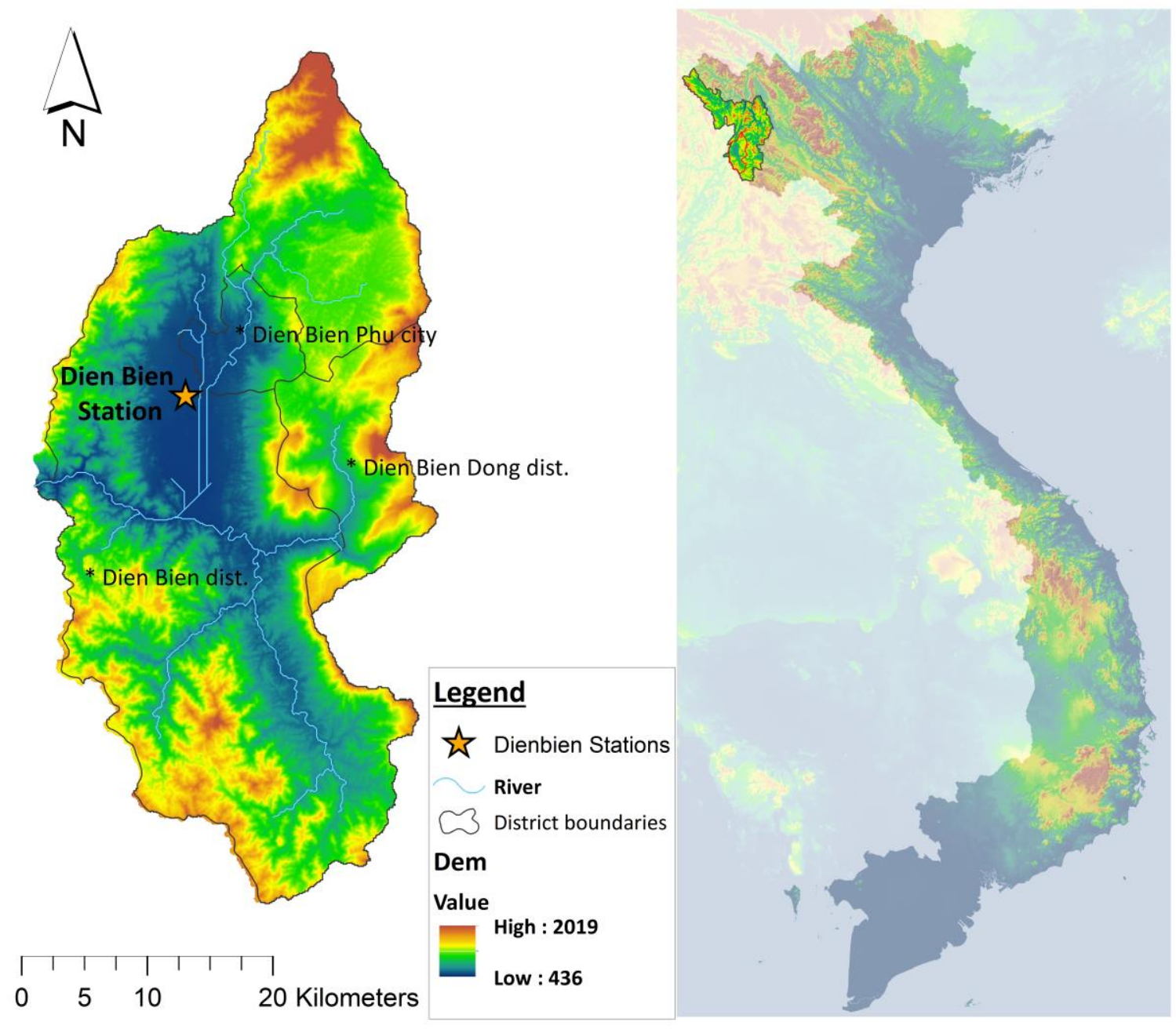

Fig 1. Study area

\subsection{Data collection}

In this study, the datasets comprise the physical characteristics (digital elevation model, soil, and land use) of the basin, and observation of time series (climate and hydrology) (Table 1). 
Digital elevation model (DEM) was used to calculate slope length, flow accumulation and flow direction, and was further used to delineate the basin, sub-basin boundaries, and stream networks (Nilawar and Waikar 2018). In this study, DEM with 50m resolution was provided by Ministry of Natural Resources and Environment, Vietnam. Slope map was generated from DEM into five classes, viz. $0^{\circ}-5^{\circ}$ (Very Gentle), $5^{\circ}-10^{\circ}$ (Gentle), $10^{\circ}-20^{\circ}$ (Moderate), $20^{\circ}-35^{\circ}$ (Moderate to Steep) and $>35^{\circ}$ (Very Steep). It has been found that most of the catchment area has moderate to step and very steep slope and it covers about $65-75 \%$ of the total catchment area but the rest of region especially near the origin of river. This high-altitude area contributes to a significant amount of soil erosion as well as high runoff, especially during monsoon periods may be partly due to inadequate management practices.

Soil data obtained from MONRE's soil investigations in 2005 (table 1) was used to formulate soil input data. In order to assign more representative Northwestern region specific soil properties and minimize the number of HRUs modeled, the areas of each MONRE soil map unit were tabulated and soil properties were derived by comparing the soil units of the Mekong River Commission (MRC) [3]. The result of this approach was to estimate soil properties that were consistent with the average northwestern provinces soil properties.

Land use/Land cover (LULC) Map

In this study, the historical land use/land cover map of 1992 and were procedure by using Landsat satellite images at Path/Row-128/55 and 129/45 in digital format acquired in the respective year. There were 9 types of land use in the study area with the most common agricultural land uses in the basin are known to be evergreen forest, open forest, mixed forest, perennial crop, paddy field, field crop, urban, water body and aquaculture, and other land. Land use change analysis was performed by overlaying classified land use maps of two-time periods using ArcMap 10.1 version.

Climate data and hydrology

Daily climate and hydrology at the gauging station was collected from Institute of Meteorology Hydrology and Environment, and Center for Environment Monitoring in the northwest region for the period 1990-2015 as shown in figure 1. Daily climate inputs for the period from 1990-2015 were collected including minimum and maximum temperature, precipitation, solar radiation, wind speed, and relative humidity. Temperature data and precipitation data from 1 station within the area were available. Additional climates variables such as solar radiation, wind speed and relative humidity inputs, were generated from weather generator using monthly values from the nearest standardized weather station. Monthly flow was collected in the period from 1990-2015 for calibration and validation.

\section{Climate Change Scenarios}

Climate change scenarios were downscaled from different General Circulation Models (GCMs) obtained from CMIP5 data set. Climate change scenarios for Viet Nam are constructed using 5 regional climate models (AGCM/MRI, PRECIS, CCAM, RegCM, clWRF). In which, PRECIS shows the best skill (Hiep, 2015). Therefore, temperature change scenarios are constructed by ensemble of all members, while rainfall change scenarios are built by ensemble of 3 PRECIS members. In the northwestern provinces, RCP4.5 scenario was selected in this study for twenty-year average changes for the early 21 st century (near term, 2016 - 2035).

Table 1: Data and Sources

\begin{tabular}{llll}
\hline SN Data & Sources & $\begin{array}{l}\text { Spatial/Temporal } \\
\text { Resolution }\end{array}$ & Number/Time Period \\
\hline
\end{tabular}




\begin{tabular}{|c|c|c|c|c|}
\hline \multicolumn{5}{|c|}{ Physical Characteristics of the Catchment } \\
\hline 1 & DEM & MONRE & $50 \mathrm{~m}$ & \multirow{5}{*}{2 maps - 1992,2015 } \\
\hline 2 & Soil & MONRE & $1: 1.000 .000$ & \\
\hline \multirow[t]{3}{*}{3} & \multicolumn{3}{|l|}{ Land use } & \\
\hline & 1992 & Landsat 5 TM & $30 \mathrm{~m} \times 30 \mathrm{~m}$ & \\
\hline & 2015 & Landsat 8 OLI_TIRs & $30 \mathrm{~m} \times 30 \mathrm{~m}$ & \\
\hline \multicolumn{5}{|c|}{ Time series observations } \\
\hline 1 & \multicolumn{2}{|l|}{$\begin{array}{l}\text { Meteorology } \\
\text { (Precipitation, } \\
\text { Temperature, } \\
\text { solar radiation, } \\
\text { wind speed, and } \\
\text { relative } \\
\text { humidity) }\end{array}$} & Point/daily & $\begin{array}{l}\text { Dien Bien station (1990- } \\
\text { 2015) }\end{array}$ \\
\hline 2 & \multicolumn{2}{|l|}{$\begin{array}{l}\text { Hydrology } \\
\text { (monthly flow) }\end{array}$} & Point/daily & $\begin{array}{l}\text { Dien Bien station (1990- } \\
\text { 2015) }\end{array}$ \\
\hline \multicolumn{5}{|c|}{ RCM data for future climate projections } \\
\hline 1 & PRECIS & Hadley Centre - UK & $0.5 \%$ Daily & $(\mathrm{RCP} 4.5)$ \\
\hline
\end{tabular}

\section{Methodology}

The methodology of this study divides two main parts of using Remote Sensing and SWAT modeling. The first part presents the steps in quantifying land use change from 1992 to 2015 and setting up the SWAT model, model running, model calibration and validation. Model application focused on simulation of hydrological processes based on the variations in land use in the past. In addition, special attention was given to simulation hydrological processes (ET, surface runoff, base flow, water yield) for long term under projected land use and climate change scenarios. The principle impacts of hydrological processes were not only land use but also climate change. Therefore, the objectives of this study were to evaluate the separated and combined impacts of land use change and climate variability on hydrology. It was very important to understand hydrological responses to these changes in order to develop strategies for land use planning and water management. The second part of the study was to predict land use scenarios based on the population growth and socio-economic development as well as land use demands and plans in the study area. SWAT modeling was selected to predict the impacts of projected land use and climate scenarios in 2030 on hydrological considering the socioeconomic development and population growth in the study area.

\subsection{Land use classification}

Satellite images from year 1992 and 2015 were processed by using Landsat satellite images at Path/Row-128/55 and 129/45 in digital format acquired in the respective years. Landsat 5 TM data acquired on 02 March 1992 was downloaded from http://glovis.usga.gov/ and used to process land use map of 1992. Landsat 8 OLI_TIRs acquired on 09 March 2015 was used to procedure land use map of 2015. Images were acquired during dry season to get less cloud cover. Due to the time lapse between the satellite images and field visit, the field data was collected mainly to provide second source of information. Confirmation from senior local officials and familiarity of the study area is the most valuable data to refine the preliminary classified land use map. Moreover, supporting data were collected from physical copies of land use maps for year 1992 (scale 1:25.000), and Google Earth captures which covered parts of study area. These data were used as references for training sites selection and ground truth validation, and to fill in land use data for unclassified area. A common method of change detection is post-classification image comparison [15]. Land use change analysis was performed by overlaying classified land use maps of two-time periods obtained from digital classification of satellite data by using ArcMap. The area changed from each class to others 
was computed.

\subsection{SWAT model application to assess the impacts of climate and land use change on hydrological responses}

\subsubsection{SWAT model}

The Soil and Water Assessment Tool (SWAT), is a physically based, continuous-time, semidistributed model designed to simulate and analyze the impact of land use, climate change and human activities on hydrological processes based on the changes of precipitation, evaporation and land cover [1,16]. The input data required for SWAT include weather data, a land-use map, a soil map, and a Digital Elevation Map (DEM) (Table 1). The model set-up consists of five steps: (1) data preparation, (2) sub-basin discretization, (3) HRU definition, (4) parameter sensitivity analysis, and (5) calibration and validation. Sensitivity analysis was carried out to identify the most sensitive parameters for model calibration using Latin Hypercube One-factor-At-a-Time, an automatic sensitivity analysis tool implemented in SWAT [1]. Those sensitive parameters were calibrated including CN2 (SCS runoff curve number for moisture condition), ALPHA_BF (base flow recession constant), ESCO (soil evaporation compensation factor), SOL_AWC (available water capacity of the soil layer), GW_REVAP (re-evaporation coefficient), GWQMN (threshold water level in shallow aquifer for base flow), ESCO (soil evaporation compensation factor), EPCO (plant uptake compensation factor), $\mathrm{CH} \_\mathrm{K} 2$ (effective hydraulic conductivity of main channel), SOL_K (soil conductivity), SOL_Z (Depth from soil surface to bottom of layer), and SLSUBBSN (Average slope length). (Table 2).

Table 2 Value of parameters used for calibration

\begin{tabular}{lllrrrr}
\hline No & Name & Method & Min & Max & Original value & Fitted value \\
\hline $\mathbf{1}$ & CN2 & Relative (r) & $-20 \%$ & $+20 \%$ & 63.97 (Average) & No changes \\
$\mathbf{2}$ & ALPHA_BF & Replace (v) & 0 & 1 & 0.048 & 0.075 \\
$\mathbf{3}$ & GW_DELAY & Replace (v) & 10 & 100 & 31 & 43.75 \\
$\mathbf{4}$ & GWQMN & Replace (v) & 0 & 2 & 0 & No changes \\
$\mathbf{5}$ & REVAPMN & Replace (v) & 0 & 100 & 0 & 67.50 \\
$\mathbf{6}$ & GW_REVAP & Replace (v) & 0.02 & 0.2 & 0.02 & No changes \\
$\mathbf{7}$ & ESCO & Replace (v) & 0 & 1 & 0.95 & 0.575 \\
$\mathbf{8}$ & EPCO & Replace (v) & 0 & 1 & 1 & 0.225 \\
$\mathbf{9}$ & CH_K2 & Replace (v) & -0.01 & 100 & 0 & 22.50 \\
$\mathbf{1 2}$ & SOL_ALB() & Relative (r) & -1 & 1 & Many value & No changes \\
$\mathbf{1 3}$ & SOL_AWC() & Relative (r) & -1 & 1 & Many value & No changes \\
$\mathbf{1 4}$ & SOL_K() & Relative (r) & -1 & 1 & Many value & $45 \%$ \\
$\mathbf{1 5}$ & SOL_Z() & Relative (r) & -0.2 & 0.2 & Many value & $-35 \%$ \\
$\mathbf{1 6}$ & SLSUBBSN & Relative (r) & -0.2 & 0.2 & Many value & $55 \%$ \\
\hline
\end{tabular}

Note: $r$ = Relative (Multiply By/ $x$ ); $v$ = Replace value

In term of calibration and validation model, three indicators were used to evaluate model performance: Nash-Sutcliffe efficiency (NSE); Observation's standard deviation ratio (RSR); and percent bias (PBIAS) [1]. The equations for the above-mentioned indicators were given below.

$N S E=1-\left[\sum_{i=1}^{n}\left(Q_{o b s}^{i}-Q_{s i m}^{i}\right)^{2}\right] /\left[\sum_{i=1}^{n}\left(Q_{o b s}^{i}-\bar{Q}_{s i m}^{i}\right)^{2}\right]$ 
where, $n$ is the number of time steps, $Q_{o b s}^{i}$, and $Q_{\text {sim }}^{i}$ are the observed and simulated data, respectively, on the $i^{\text {th }}$ time step, and $\bar{Q}_{o b s}$ is the mean of observed data $\left(Q_{o b s}^{i}\right)$ across the $n$ evaluation time steps.

$$
R S R=\frac{R M S E}{S T D E V_{o b s}}=\frac{\sqrt{\left[\sum_{i=1}^{n}\left(\left(Q_{o b s}^{i}-Q_{s i m}^{i}\right)^{2}\right)\right]}}{\sqrt{\left[\sum_{i=1}^{n}\left(Q_{o b s}^{i}-\bar{Q}_{o b s}\right)^{2}\right]}}
$$

where, $n$ is the number of events, $Q^{i}$ obs, and $Q^{i}$ sim are the observed and simulated data on the $i^{\text {th }}$ time events, $\bar{Q}_{o b s}$ is the mean of observed data across the $n$ evaluation time steps

$$
P B I A S=\sum_{i=1}^{n}\left(Q_{o b s}^{i}-Q_{s i m}^{i}\right) \times 100 / \sum_{i=1}^{n} Q_{o b s}^{i}
$$

where, $n$ is the number of time steps, $Q^{i}$ obs, and $Q_{s i m}^{i}$ are the observed and simulated data, respectively, on the $i^{\text {th }}$ time step.

The performance of the model is acceptable when RSR is close to 0, NSE $\geq 0.65$ and PBIAS $\leq 10$ (Moriasi et al. 2012). The optimal value of NSE is equal to 1 indicating the model performs almost perfectly. On the other hand, NSE less than or close to 0 indicates the model is a worse predictor of the measured data. The optimal value of PBIAS is 0 ; positive values indicate model underestimation; and negative values indicate model overestimation. [12]

\subsubsection{Model application}

To assess the impacts of climate and land use change on hydrological responses, the approach of one factor at a time was used (i.e., changing one factor at a time while holding others constant). Meteorological data of the three time-slices of 1992-2003, 2004-2015, and 2016-2030 were selected, and each time-slice included one land use map. The land use maps of 1992, 2015, and 2030 were used to represent the land use patterns of 1992, 2015, and 2030 for the three time-slices, respectively. The calibrated SWAT model was run for each of the five combinations of three timeslices and three land use maps (called five scenarios hereafter). The influences of the climate and land use change were quantified by comparing the SWAT outputs of the four scenarios as follows:

S1:1992 land use and 1992-2003 climate;

S2:2015 land use and 1992-2003 climate;

S3:1992 land use and 2004-2015 climate;

S4:2015 land use and 2004-2015 climate;

S5:2030 land use and 2016-2030 climate (based on projected land use and climate change scenarios).

From the scenarios above we can see that: S1 and S2 are considered as the effect of climate change on hydrological processes; S3, S4 are considered as the impacts of land use change on hydrological processes; S5 is considered as the impacts of both land use and climate change on hydrological processes

\section{Results}

\subsection{Land Use/Land Cover Change from 1992-2015 and 2015-2030}

Classified land use map for 1992 and 2015 are presented in Fig 2. In recent decades in the Nam 
Rom River basin, rapid land use change has occurred and is known for its traditional farming system called "composite swidden farming". The major land use types with the most significant change are occurring in five land use classes: open forest (FRSD), mixed forest (FRST), field crop (FCRP), paddy (PDDY), field crop and urban (URBN). From 1992 to 2015, the proportional extent of FSRD, PDDY, and URBD, was from 15739.7 ha to 39876.9 ha (18.1\%), 9292.7 ha to 4939.0 ha (1.2\%), and 2175.3 ha to 4196.9 ha (1.5\%), respectively. On the other hand, the proportion of FRST, ORCD and BARR dramatically decreased from 34849.4 ha to 14084.8 ha $(15.5 \%), 17729.5$ ha to 14127.8 ha $(2.7 \%)$, and 4652.4 ha to 1323.8 ha $(2.5 \%)$, respectively. The reason for these changes was the expansion of paddy rice because Dien Bien's rice considered to have high quality and efficiency [15]. According to annual reports and interview data, many parts of mixed forests and perennial crops were converted to agricultural land, and timber was exploited and there was a lack of regulation to protect and sustainably use forest resources which led to a reduction of forest cover. The expansion of paddy rice and urbanization of the area were due to population pressure, food demand and transition from a subsistence and planned economy towards market-oriented agriculture.

Land use scenarios (2030) were developed based on the population growth and socio-economic development as well as land use demands and plans in the study area. The projected population in 2030 of Dien Bien province is approximately about 694,778 people in total with population density of 73 people per square kilometers. At the Nam Rom river basin, population density in 2030 is estimated to be about 153 people per square kilometers [6], corresponding to a population of 204.340. Considerations were made for the purpose of predicting land use changes growth rate of about 1.22 times, and food security at $50 \%$ in paddy field and $15 \%$ in urban land. In addition, ongoing changes in land use types in the Nam Rom river basin are: utilizing vacant lands for all other purposes of land use especially urban land; converting inefficient upland fields into forest land or orchard; converting mixed forest, open forest to evergreen forest if possible; converting lowland to paddy fields and expanding existing residential neighborhoods by using nearby lands. Assumption of this trend is maintained in the future. In addition, the land use scenarios as dependent and independent variables were prepared in individual layer based on various sources such as distance to cities or rivers or road, elevation, slopes, population density, availability of irrigation support, land suitability class for rice, and land tenure status. A binary logistic regression was used to model the probability of a pixel of agriculture land to be converted to other lands (built up area) as a function of set of hypothesized determinants[8.15]. In order to assess the relative importance among the determinants, we standardized the scale independent variables prior to performing the logistic regression. Its value ranges from 0.5 for a model that assigns the probability at random, to 1 for a model that perfectly assigns the probability of land conversion. The projected land use in 2030 of the Nam Rom river basin was created following baseline land use in 2015 (Fig 2). 

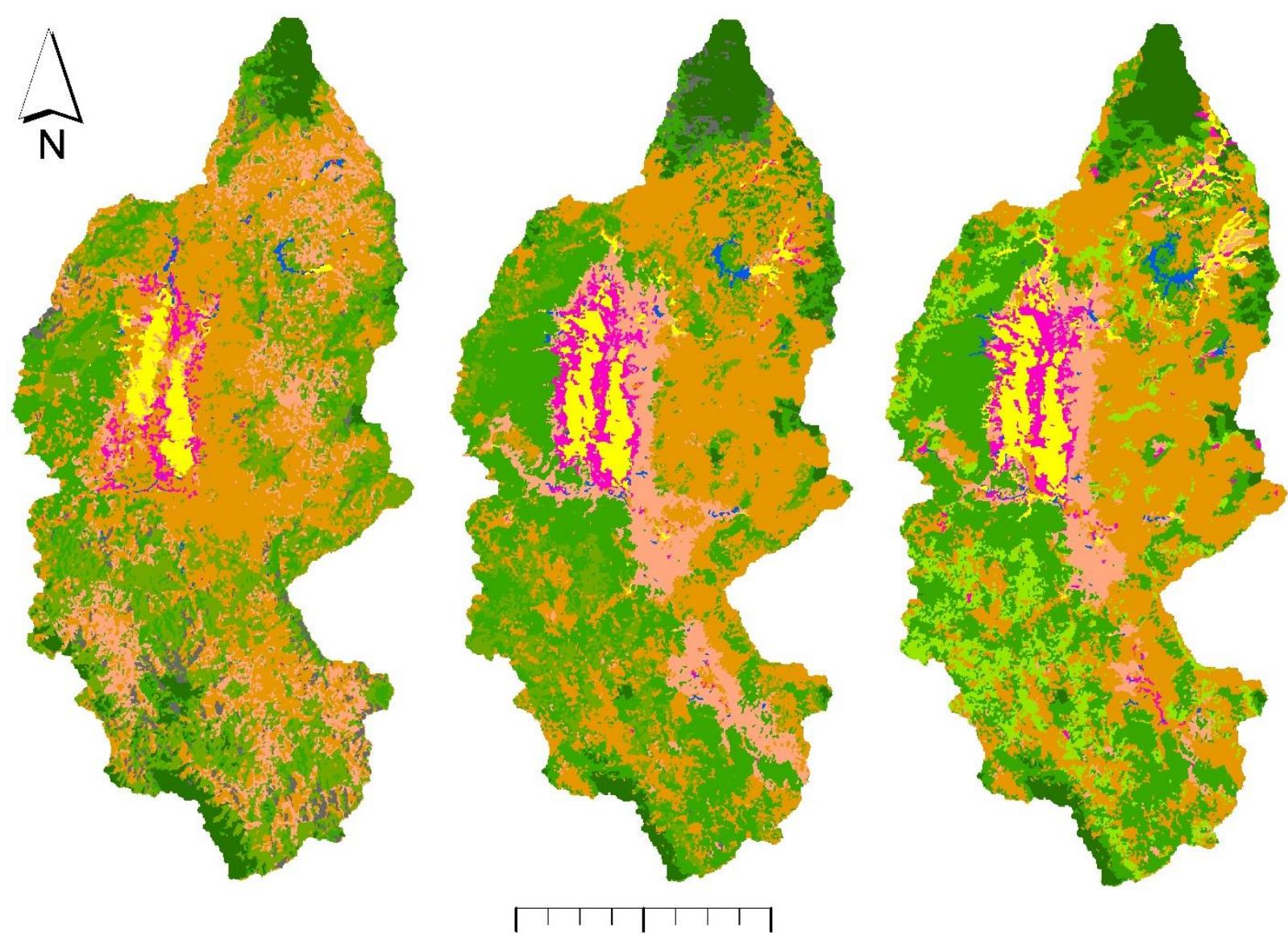

051020 Kilometers

1. Evergreen Forest

2. Open Forest
3. Mixed Forest

4. Perennial crop
5. Paddy Field

6. Field crop

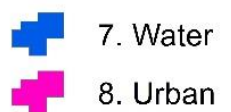

9. Other land

Fig 2. Land use maps the study area in 1992 (left), 2015 (middle) and 2030 (right)

\subsection{Model Calibration and Validation}

Table 3. Model performances for the monthly simulation of runoff

\begin{tabular}{lcc}
\hline \multicolumn{1}{c}{ Indicator } & \multicolumn{2}{c}{ Runoff } \\
& $\begin{array}{c}\text { Calibration } \\
(\mathbf{1 9 9 2 - 2 0 0 3 )}\end{array}$ & $\begin{array}{c}\text { Validation } \\
\mathbf{( 2 0 0 4 - 2 0 1 5 )}\end{array}$ \\
\cline { 2 - 3 } RSR & 0.49 & 0.60 \\
NSE & 0.76 & 0.65 \\
$\mathbf{R}^{\mathbf{2}}$ & 0.75 & 0.62 \\
PBIAS (\%) & 6.76 & 8.37 \\
\hline
\end{tabular}

The model was run for a period of 25 years (1990-2015) by considering the first 3 years as warm up time of the model. Calibration and validation were performed to improve model performance at the Dien Bien gauging station. Results showed a good correlation between observed and simulated flow during both the calibration and validation period (Fig 4 and 5). Taking into account the criteria of Moriasi et al. (2012) the SWAT model showed good to very good performance for monthly runoff prediction (Table 3). For runoff, Nash-Sutcliffe coefficient of efficiency (NSE), observation 
standard deviation ratio $\left(\mathrm{R}^{2}\right)$, and percent bias (PBIAS) were $0.76,0.76$, and 6.76, respectively for the calibration period and $0.64,0.65$, and 8.37 for the validation period. Both the $\mathrm{R}^{2}$ and NSE values were 0.76 and 0.75 in the runoff simulation during the calibration period; however, the values of the two indices decreased in the validation, with the peak flow overestimated for summer. In addition, the observed runoff showed a summer peak almost every year; this feature was not shown in the model simulation. The performance of SWAT for the calibration period was better than for validation period. A positive bias was found for the both calibration and validation period. This can also be seen in the regression plots (Fig 4) where the linear trend line computed for the calibration period was closer to the 1:1 line than in the validation period (Fig 4). The above results indicated that the SWAT model can be successfully used for predicting the effects of land use and climate changes in the study area.

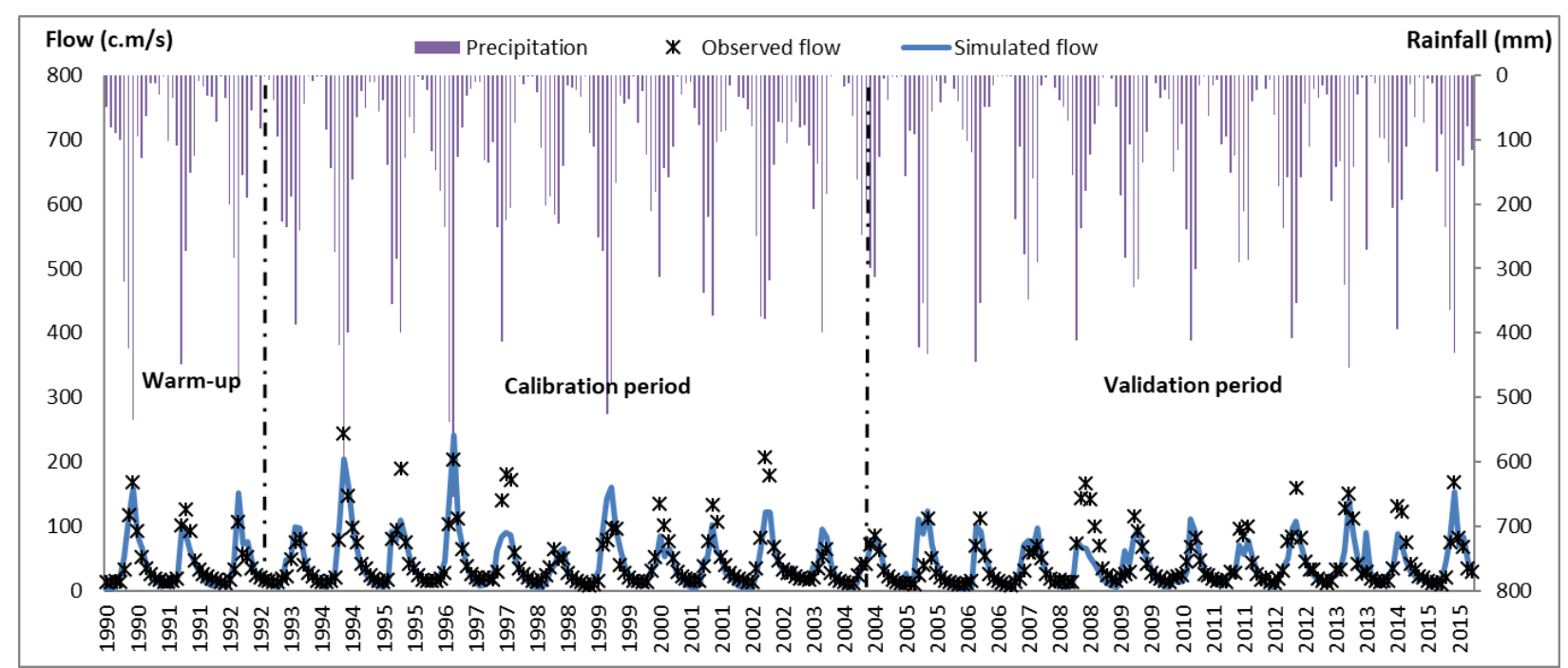

Fig 3. Monthly observed and simulated flow from 1992 to 2015

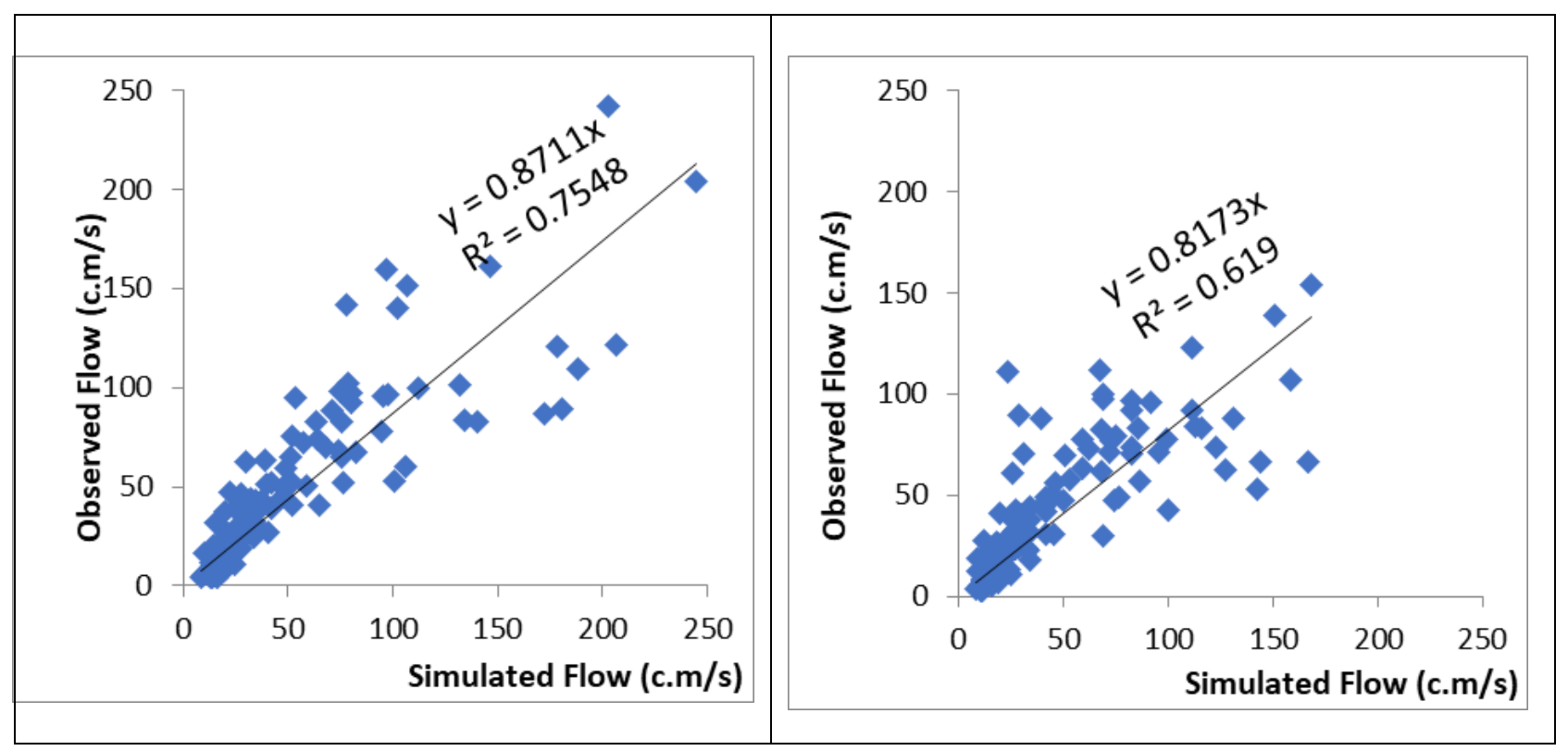

Fig 4. Relationship between monthly observed and simulated flow during Calibration (1992-2003) and Validation period (2004-2015) 


\subsection{Impacts of the historical land-use change and climate change on hydrological processes}

In order to investigate impacts of land use change on hydrological components, the simulation was implemented by using land use of 1992 and 2015 and the climate change of 1992-2015. Under the impact of land use change, ET, percolation, groundwater, and water yield increased considerably by $1.8 \%, 5.8 \%, 5.8 \%$, and $2.3 \%$ respectively. Aside from this, surface flow decreased $4.3 \%$. The above results indicated that deforestation and expansion of field crop and paddy rice may possibly be the causes of these changes. In addition, forest cover stored more water than any other types of land use [17] and infiltrated rate of forestland is the largest in comparison with other types of land use. The results are similar to the study findings conducted by Phan et al. (2010) and Khoi and Suetsugi (2014). Phan et al. (2010) indicated that $11.07 \%$ forest land conversion to agricultural land caused increase in stream flow by $3.93 \%$. Khoi and Suetsugi (2014) also reported that the increase in average annual stream flow (1.2\%) was due to rapid deforestation and expansion of agriculture land.

To assess the impacts of climate change on hydrological components, the model simulation was implemented by comparing two scenarios including land use of 1992 and the two different climate periods: 1992-2003 and 2004-2015. In Fig 5, the annual precipitation decreased significantly by $7.5 \%$ in two different periods resulting to a decrease in all hydrological components including ET $(2.3 \%)$, percolation $(9.8 \%)$, surface runoff $(11.5 \%)$, ground water flow $(10.5 \%)$, and water yield $(10.8 \%)$. This could be due to the decrease in precipitation during 2004-2015 compared with the 1992-2003 period. With the change in precipitation, the annual surface runoff decreased by $11.0 \%$ (Fig 5). Considering climate variability impacts on seasonal change, the flow discharge significantly decreased by $14.8 \%$ in the wet season and increased by $0.3 \%$ in the dry season. These results can be attributed to the changes in seasonal precipitation such as decreasing precipitation in the wet season. Moreover, as we observed, the rainy season both quantity and intensity started earlier in May instead of August.

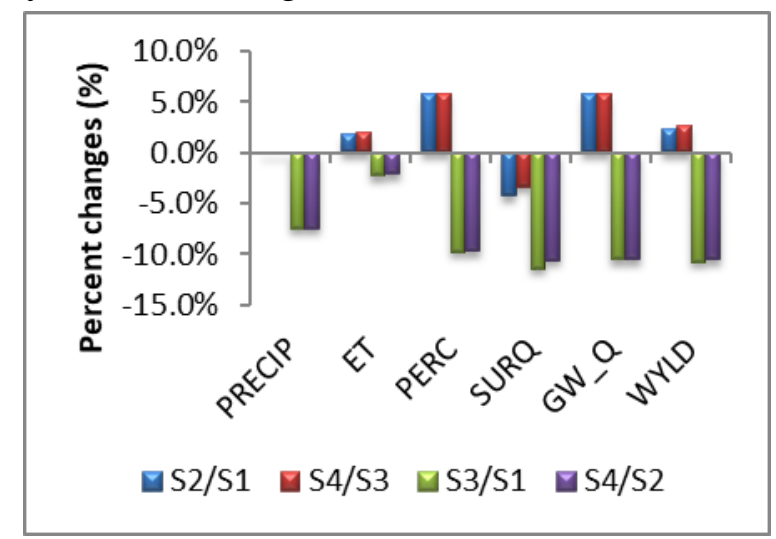

Fig. 5. Annual changes of hydrological processes

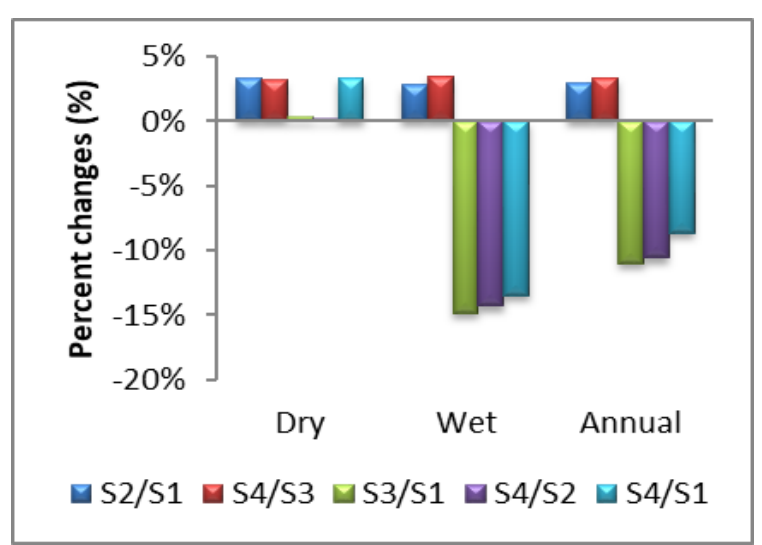

Fig. 6. Seasonal changes of hydrological processes

\subsection{Contribution of changes for combined LULCs and climate change on hydrological components from $1992-2015$ in the sub-basin}

The spatial distribution of changes for six groups (i.e. open forest, mix forest, perennial crop, paddy, field crop, and urban) and five simulated hydrological components (i.e evapotranspiration, percolation, surface runoff, ground water, and water yield) between LULC maps in 1992 and 2015 are shown in Fig 7. 


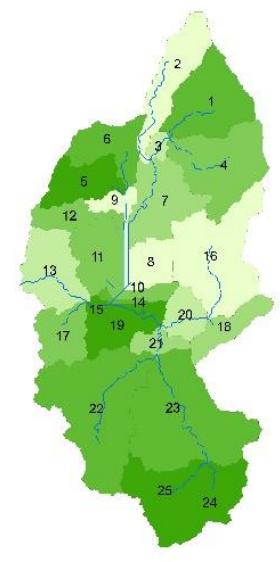

Open Forest \% / Sub.Area

$-0.01-0.02$
$0.02-0.05$

-1] 0.09

- $0.14-0.17$

4. $0.21-0.28$

푸 $0.35-0.43$

Max increase in sub 15 (42.83\%)

Max decrease in sub $9(-0.54 \%)$

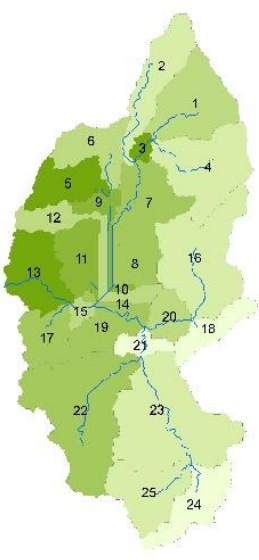

Mixed Forest \% / Sub.Area

$$
\begin{array}{r}
-0.40 \cdot-0.31 \\
-0.27-0.20
\end{array}
$$

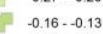

$=-0.10-0.08$

$-0.02-0.00$

$=0.06$

Max increase in sub $3(6.28 \%)$

Max decrease in sub $18(-39.77 \%)$
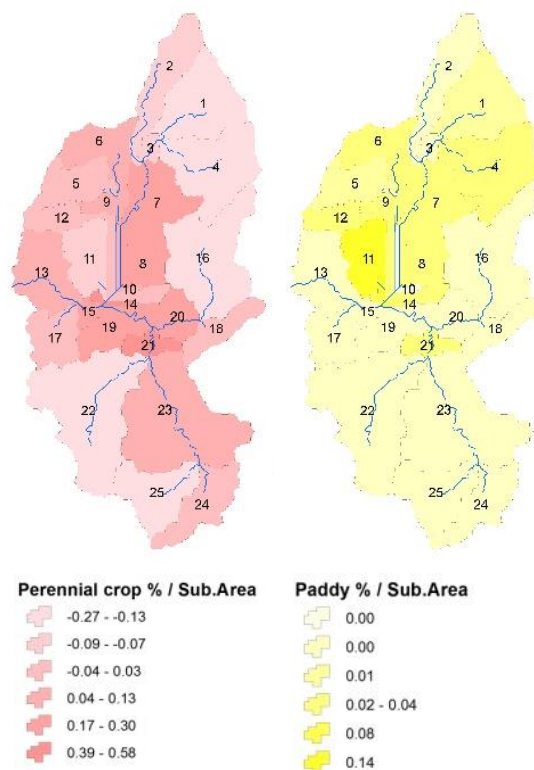

Max increase in sub $21(58.22 \%)$

Max decrease in sub $1(-27.45 \%)$

Paddy \% / Sub.Area

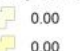

0.00

0.01

$0.02 \cdot 0.04$
0.08

1. 0.14

Max increase in sub $11(13.69 \%)$

Max decrease in sub $10(-0.27 \%)$

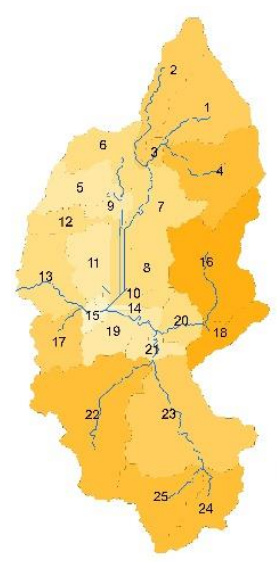

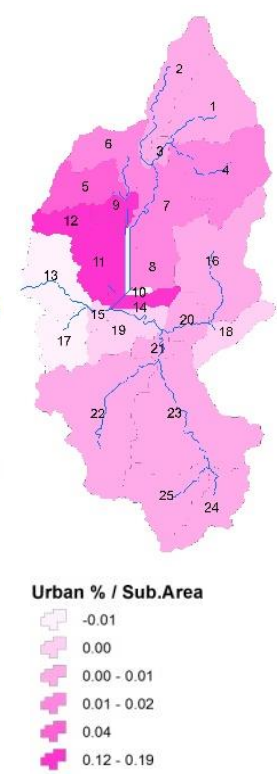

Max increase in sub 16 (40.75\%)

Max decrease in sub $14(-76.77 \%)$
Max increase in sub 15 (18.73\%)

Max decrease in sub $9(-0.96 \%)$

Fig 7. Spatial distribution of deviation of land use classes from $1992-2015$

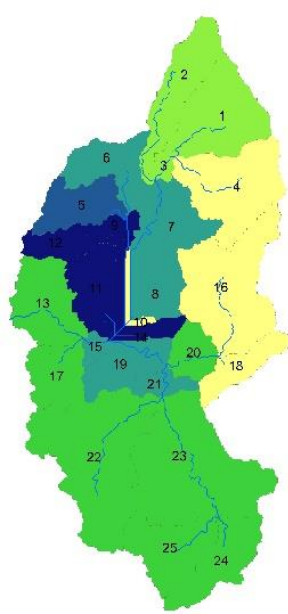

Evapotranspiration (mm)

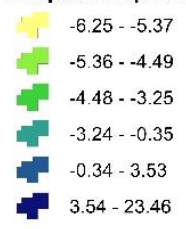

Max increase in sub $9(23.5 \mathrm{~mm})$

Max decrease in sub $16(-6.3 \mathrm{~mm})$
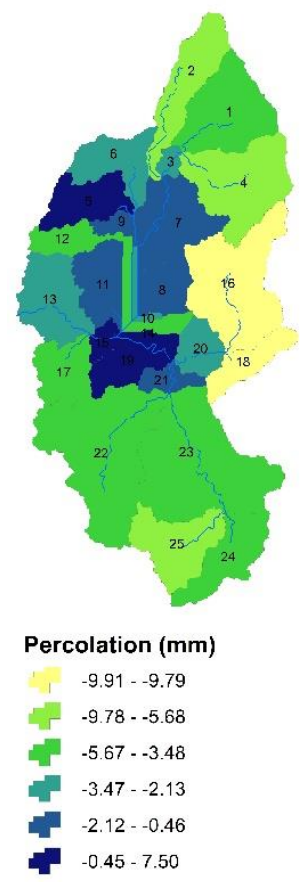

Max increase in sub $14(7.5 \mathrm{~mm})$

Max decrease in sub 18 (-9.9 mm)

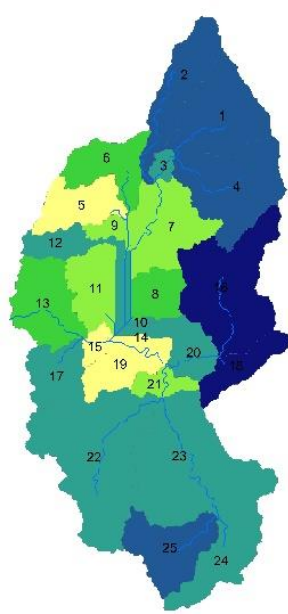

Surface Runoff (mm)

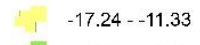

ㄷ. $-11.32 \cdot-5.87$

드 $\quad-5.86-4.01$

H. $-4.00--2.00$

$-1.99-2.08$

$2.09-5.82$

Max increase in sub $16(5.8 \mathrm{~mm})$

Max decrease in sub $14(-17.2 \mathrm{~mm})$

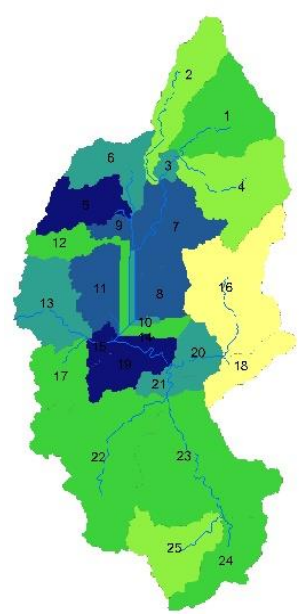

Groundwater (mm)

$$
\begin{array}{r}
-9.78--9.67 \\
-9.66--5.80 \\
-5.79--3.72 \\
-3.71--2.23 \\
-2.22--0.86 \\
-0.85-6.59
\end{array}
$$

Max increase in sub $14(6.6 \mathrm{~mm})$

Max decrease in sub $18(-9.8 \mathrm{~mm})$

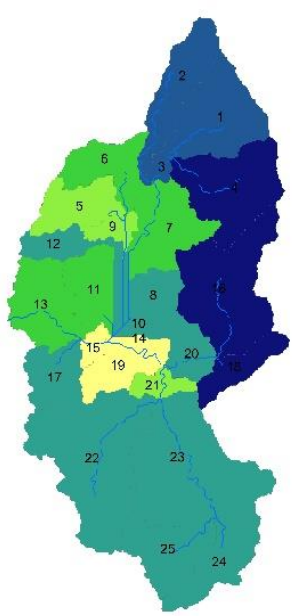

$$
\begin{array}{r}
\text { Water yield (mm) } \\
-10.44--9.50 \\
-9.49--8.44 \\
-8.43--7.34 \\
-7.33--6.48 \\
-6.47--5.77 \\
-5.76--4.11
\end{array}
$$

None sub increase

Max decrease in sub 14 (-10.4 mm)

Fig 8. Spatial distribution of deviation of combined land use and climate change for hydrological components in the period of $1992-2015$ 
Open forest, paddy rice, field crop, and urban expansion mainly occurred in sub-basin 15, 11, and 16 at the center of Dien Bien district. The increased paddy rice was mainly distributed in the Dien Bien's deep hollow. The most significant increases of surface runoff (i.e max $5.8 \mathrm{~mm}$ ), ground water (i.e $\max 6.6 \mathrm{~mm}$ ), evaporation (i.e $\max 23.5 \mathrm{~mm}$ ), percolation (i.e. $\max 7.5 \mathrm{~mm}$ ), largely matching the spatial distribution pattern expansion of urban, paddy field, and field crop, which were confirmed by the positive high correlation between its expansion and increase of surface runoff (Fig 9). The decrease of surface runoff and water yield in sub-basin 14 and 5 correspond to where the majority of field crop was replaced by forest.

\subsection{Impacts of projected land-use planning and climate change on hydrological components in the basin scale}

Surface flow and water yield showed higher sensitivity to land use and climate changes. Surface runoff is projected to increase $7.4 \%$ and water yield is projected to increase $3.8 \%$ in the future. In addition, other components (ET, ground water, and percolation) are supported to slightly increase in the period of 2015-2030 due to slight increase in precipitation (3.1\%) (Fig. 9).

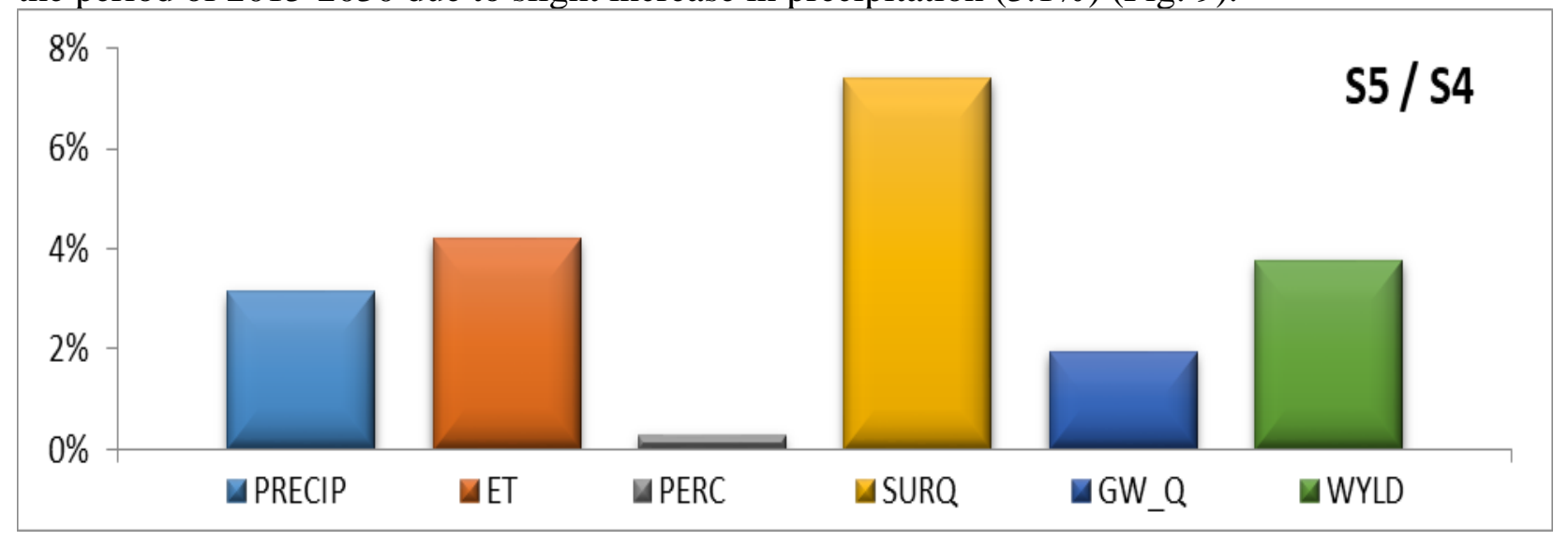

Fig 9. Annual changes of hydrological processes under Projected Land Use and Climate Change Scenarios

\subsection{Impacts of projected land-use planning and climate change on hydrological components in the sub-basin scale}

Similar to the historical land use and climate change, open forest, mixed forest, paddy rice, paddy, and urban expansion mainly occurred in the northeastern Dien Bien (i.e in sub-basin 4, 3, and 1). The increased field crop was mainly distributed in the northwestern and the southern Dien Bien. Due to increase of forest cover and in combination of implementing soil conservation practices, the maximum of surface runoff (i.e $\max 6.7 \mathrm{~mm}$ ), ground water (i.e $\max 4.4 \mathrm{~mm}$ ), evaporation (i.e $\max$ $9.1 \mathrm{~mm}$ ), and percolation (i.e. $\max 3.8 \mathrm{~mm}$ ) decreased compared to land use in the period of 19922015 and mainly occurred in sub-basin 14, 1, 20 and 9, largely matching the spatial distribution pattern expansion of FRSE, FRSD, and paddy which were confirmed by the negative high correlation between its expansion and decrease of surface runoff (Fig 10 and 11). The decrease of surface runoff in sub-basin 14 and 20 correspond to where the majority of field crop was replaced by forest. 


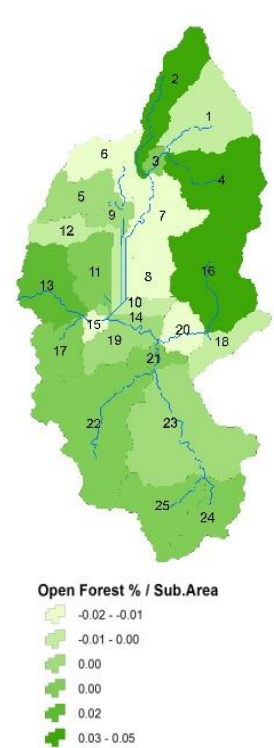

Max increase in sub 4 (4.9\%)

Max decrease in sub $6(-2.3 \%)$

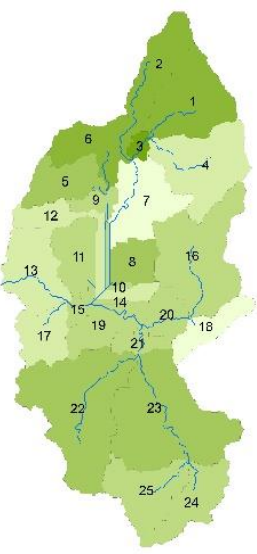

Mixed Forest \% / Sub.Area $-0.03-0.02$
$-0.01-0.00$ 0.00

0.01 Nin $0.03 \cdot 0.04$ - 0.12

Max increase in sub $3(12.1 \%)$

Max decrease in sub $18(-3.1 \%)$
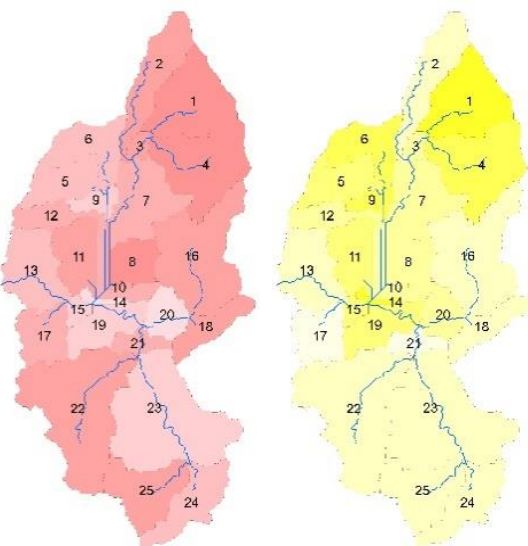

Perennial crop \% / Sub.Are II -0.19

$-0.15-0.10$
$-0.07-0.05$

$-0.07--0.05$
$-0.03--0.02$

$-0.03-0.02$
$-0.01-0.00$

$0.03-0.04$

Max increase in sub $1(3.9 \%)$

Max decrease in sub $20(-18.8 \%)$

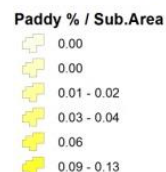

Max increase in sub $14(12.8 \%)$

Max decrease in sub $17(-76.8 \%)$

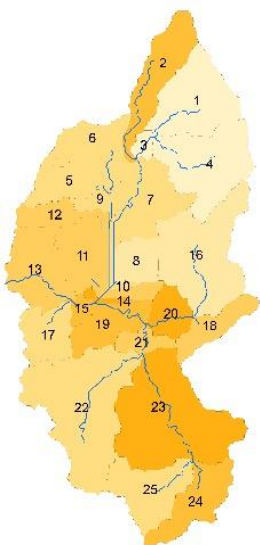

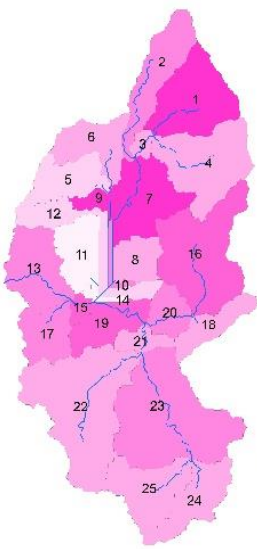

Field crop \% / Sub.Area $-0.17 \cdot-0.13$
$-0.05 \cdot-0.04$

$-0.05 \cdot-0.04$
$-0.01-0.02$

$0.03 \cdot 0.04$

$0.06 \cdot 0.07$

= $0.12 \cdot 0.20$

Max increase in sub $20(19.9 \%)$

Max decrease in sub $1(-16.8 \%)$

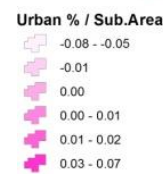

Max increase in sub $9(6.9 \%)$

Max decrease in sub $11(-8.2 \%)$

Fig 10. Spatial distribution of deviation of land use classes from $2015-2030^{*}$

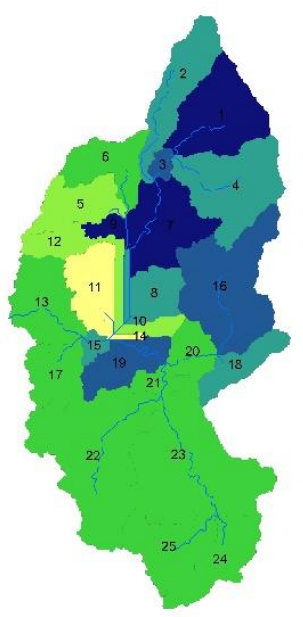

Evapotranspiration (mm)

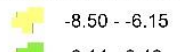

단. $-6.14-0.42$

드 $0.43-2.09$

- $2.10-3.26$

$3.27-4.17$

$4.18-9.09$

Max increase in sub $9(9.1 \mathrm{~mm})$

Max decrease in sub $11(-8.5 \mathrm{~mm})$

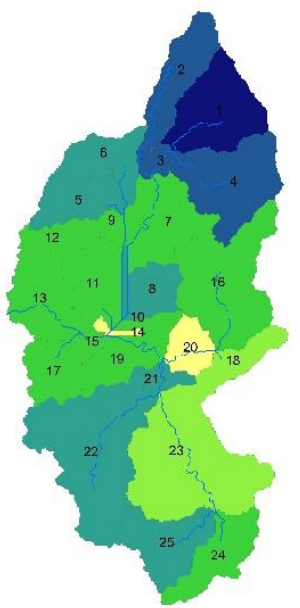

Percolation (mm)

$$
\begin{array}{ll}
-3.24--2.91 \\
-2.90--0.87 \\
-0.86-0.13 \\
0.14-0.62 \\
0.63-2.50 \\
2.51-3.79
\end{array}
$$

Max increase in sub $14(3.8 \mathrm{~mm})$

Max decrease in sub $18(-3.2 \mathrm{~mm})$

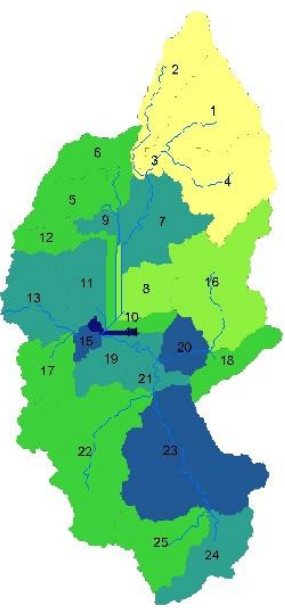

Surface Runoff (mm)

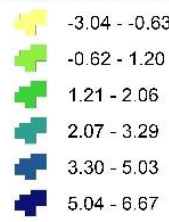

Max increase in sub $14(6.7 \mathrm{~mm})$

Max decrease in sub 1 (-3.0 mm)
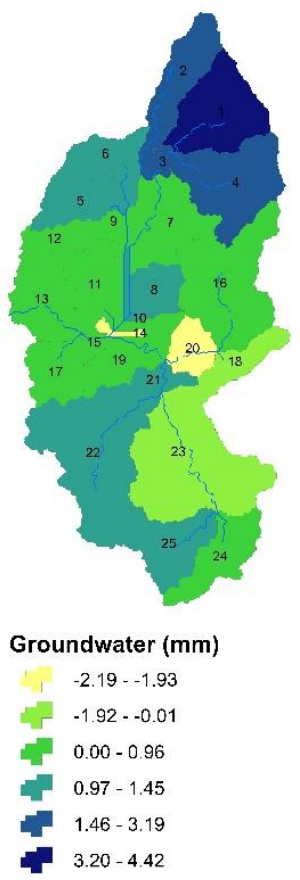

Max increase in sub 1 (4.4mm)

Max decrease in sub $14(-2.2 \mathrm{~mm})$

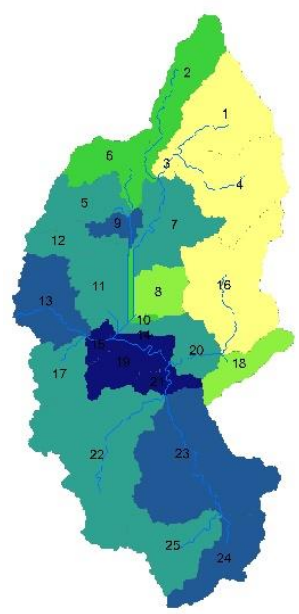

Water yield (mm
$1.33-1.72$
$1.73-2.13$
$\quad 2.14-2.74$
$\quad 2.75-3.20$
$\quad 3.21-3.52$
$-3.53-4.68$

Max increase in sub $14(4.9 \mathrm{~mm})$

None sub decrease

Fig 11. Spatial distribution of deviation of combined land use and climate change for hydrological processes in the period of 2015-2030 


\section{Conclusions}

Land use change in the study area was dominated by converting from forests (FRST and ORCD) to paddy field, open forest, and urban area. The proportional extent of FSRD, PDDY, and URBD, was from 15739.7 ha to 39876.9 ha $(18.1 \%), 9292.7$ ha to 4939.0 ha (1.2\%), and 2175.3 ha to 4196.9 ha (1.5\%), respectively. On the other hand, the proportion of FRST, ORCD and BARR dramatically decreased from 34849.4 ha to 14084.8 ha (15.5\%), 17729.5 ha to 14127.8 ha (2.7\%), and 4652.4 ha to 1323.8 ha $(2.5 \%)$, respectively. It has been found that the major LULC changes have a strong impact on the surface runoff in the past as well as near future and hence they might be considered for water resource management plan in the study area.

The evaluation results indicated that the SWAT model accurately simulated monthly runoff and sediment yield in the study area according to Nash-Sutcliffe efficiency (NSE), Observation's standard deviation ratio (RSR), and percent bias (PBIAS) values. For runoff, NSE, $\mathrm{R}^{2}$, RSR and PBIAS were $0.76,0.75,0.49$ and 6.76 , respectively for the calibration period and $0.65,0.62,0.60$ and 8.37 for the validation period.

Land use change in the study area increased ET, percolation, groundwater, and water yield by $1.8 \%$, $5.8 \%, 5.8 \%$, and $2.3 \%$ while decreased surface flow $(4.3 \%)$ was observed due to increasing forest cover (open forest and mixed forest) in combination with decrease in precipitation. Therefore, sustainable land-use planning, especially protecting the forest efficiently in the upstream of the watershed, as well as reforestation need to be implemented in Nam Rom River Basin. In addition, it is necessary to apply suitable culture methods to the slope areas and to improve the local people's knowledge of soil and forest protection. Climate change in the period 1992-2003 and 2004-2015 with annual precipitation decreased significantly by $7.5 \%$ in two different periods resulting decrease in all hydrological components including ET $(2.3 \%)$, percolation $(9.8 \%)$, surface runoff $(11.5 \%)$, ground water flow (10.5\%), and water yield (10.8\%) due to precipitation from 2004-2015 is significant higher than 1992-2003. The impacts of climate change would also exacerbate serious problems related to water shortage in the dry season. Thus, it is necessary to incorporate adaptation to climate change into current and future water resource planning. The combination of land use and climate changes impacts caused significantly decrease surface runoff $(-16.9 \%)$, ground water ($5.7 \%)$, and water yield (-9.2\%). Overall, the changes in climate affected hydrological components more significantly and strongly than the changes in land use in the Nam Rom river basin during the 1992-2015.

In conclusion, analysis impacts of the projected land use and climate change scenarios on hydrological process in the Nam Rom river basin indicate that surface runoff is projected to increase $7.4 \%$, water yield is projected to increase $3.8 \%$, in the future. On the other hand, other components (ET, ground water, and percolation) are supported to slightly increase in the period of 2015-2030 due to slightly increase in precipitation (3.1\%). However, the changes in climate and LULCs in the future period are uncertain not only for the scenarios but also for the calibrated parameter of the hydrological model. Therefore, in the future research, it is suggested to collect more GCMs and use different LULCs simulated models to predict the future climate scenarios and LULCs scenarios, respectively. In addition, the methods used in this study to assess changes in hydrological components due to LULCs and climate change can be applied to other river basins. Finally, longer-term analysis of future changes in climate and LULC is recommended to compare possible changes on hydrological components beyond 2030. Finally, results obtained from this study could be used to provide decision makers with information as well as measures to implement appropriate watershed management and sustainable development.

\section{Acknowledgements}


Authors wish to express appreciation to all officials at the Ministry of Natural Resources and Environment, Departments of Land Management in Dien Bien district for full cooperation while collecting information; they provided significant data for this research. Special thanks extended to Ms Do Thi Thanh Duong for all the assistance and cheers. Sincere thanks are also due to other colleagues for their inspiration and suggestions. Thanks also to the farmers who spent their valuable time responding the questionnaire. We thank Ms. Nicola Louise Timbas of the University of Iowa, USA for her help in revising English. We truly appreciate the anonymous reviewers for their constructive comments. We would like to take this opportunity to express a deep sense of gratitude to International Foundation for Science (IFS), Sweden for funding this research project.

\section{References:}

1. Arnold, J. G., Moriasi, D. N., Gassman, P. W., Abbaspour, K. C., White, M. J., Srinivasan, R., ... \& Jha, M. K.. SWAT: Model use, calibration, and validation. Transactions of the ASABE, 2012, 55(4), 1491-1508.

2. Arnold, J. G., Srinivasan, R., Muttiah, R. S., \& Williams, J. R. Large area hydrologic modelling and assessment. Part I: Model development. Journal of the American Water Resources Association 1998, 34(1), 73-89.

3. Binh ND, Trung LĐ. Modelling applications for watershed management. In Proceeding: National Conference on Environment, Ministry of Natural Resources \& Environment, Hanoi, Vietnam 2005, 919-928. (In Vietnamese)

4. Boru, G. F., Gonfa, Z. B., \& Diga, G. M. Impacts of climate change on stream flow and water availability in Anger sub-basin, Nile Basin of Ethiopia. Sustainable Water Resources Management 2019, 5(4), 1755-1764.

5. Elfert, S., \& Bormann, H. Simulated impact of past and possible future land use changes on the hydrological response of the Northern German lowland 'Hunte'catchment. Journal of Hydrology, 2010, 383(3), 245-255;

6. General Statistics Office of Vietnam (GSOV) and United Nations Population Fund (UNFPA). Forecast for the population in Vietnam, News Publishing House, Ha Noi, Viet Nam. 2016, 83115 (Vietnamese).

7. Gosain, A. K., Rao, S., \& Basuray, D. Climate change impact assessment on hydrology of Indian River basins. Current science 2006, 90(3), 346-353.

8. Hoang Le Huong, Tran Trong Phuong, Ngo Thanh Son. Assessing correlation between geography and land use changes in Nam Rom River Basin, Dien Bien province. Journal of Vietnam Agricultural Science and Technology 2017, (3) 71-78 (In Vietnamese)

9. Huyen, N. T., Tram, V. N. Q., Minh, D. N., Liem, N. D., \& Loi, N. K. Assessing the impacts of climate change on water resources in the Srepok watershed, Central Highland of Vietnam. Journal of Water and Climate Change 2017, 8 (3), 524-534.

10. Huang, C., Barnett, A. G., Wang, X., Vaneckova, P., FitzGerald, G., \& Tong, S. Projecting future heat-related mortality under climate change scenarios: a systematic review. Environmental health perspectives 2011, 119(12), 1681-1690.

11. Khoi, D. N., \& Suetsugi, T. The responses of hydrological processes and sediment yield to land-use and climate change in the Be River Catchment, Vietnam. Hydrological Processes 2014, 28(3), 640-652;

12. Li, Z., Liu, W. Z., Zhang, X. C., \& Zheng, F. L. Impacts of land use change and climate variability on hydrology in an agricultural catchment on the Loess Plateau of China. Journal of hydrology 2009, 377(1), 35-42.

13. MONRE. Climate Change, Sea Level Rise Scenarios for Vietnam, VietNam Publishing House of Natural Resources, Environment and Cartography, Hanoi, Vietnam 2016, 10-73(In 
Vietnamese)

14. Moriasi, D. N., Wilson, B. N., Douglas-Mankin, K. R., Arnold, J. G., \& Gowda, P. H. Hydrologic and water quality models: Use, calibration, and validation. Transactions of the ASABE 2012, 55(4), 1241-1247.

15. Müller, D. Land-use change in the Central Highlands of Vietnam. A spatial econometric model combining satellite imagery and village survey data, Georg-August-Universität Göttingen, Göttingen, 2003, 1-192

16. Neitsch, S. L, Arnold, J. G, Kiniry, J. R, Williams, J. R. Soil and Water Assessment Tool User's manual version 2005, US Department of Agriculture - Agricultural Research Service, Temple, Texas. 2005, 205-234;

17. Ngo, T. S., Nguyen, D. B., \& Rajendra, P. S. Effect of land use change on runoff and sediment yield in Da River Basin of Hoa Binh province, Northwest Vietnam. Journal of Mountain Science 2015, 12(4), 1051-1064.

18. Nie, W., Yuan Y., Kepner, W., Nash, M. S., Jackson, M., \& Erickson, C. Assessing impacts of Land use and Land cover changes on hydrology for the upper San Pedro watershed. Journal of Hydrology 2011, 407(1), 105-114.

19. Phan, D.B., Wu, C.C. and Hsieh, S.C. Impact of climate change on stream discharge and sediment yield in northern Vietnam. Water Resources 2011, 38(6), 827-836. DOI: $10.1134 /$ S0097807811060133.

20. Saleh, Dina K., et al. Using the soil and water assessment tool (SWAT) to simulate runoff in Mustang Creek Basin, California. U. S. Geological Survey, 2009.

21. Shrestha, B., Cochrane, T. A., Caruso, B. S., Arias, M. E., \& Piman, T. Uncertainty in flow and sediment projections due to future climate scenarios for the $3 \mathrm{~S}$ Rivers in the Mekong Basin. Journal of Hydrology 2016, 540, 1088-1104;

22. $\mathrm{Tu}, \mathrm{J}$. Combined impact of climate and land use changes on stream flow and water quality in eastern Massachusetts, USA. Journal of Hydrology 2009, 379(3), 268-283.

23. Ziegler, A. D., Giambelluca, T. W., Plondke, D., Leisz, S., Tran, L. T., Fox, J., \&Vien, T. D. Hydrological consequences of landscape fragmentation in mountainous northern Vietnam: buffering of Hortonian overland flow. Journal of Hydrology 2007, 337(1), 52-67. 